\title{
REFLEXÕES SOBRE O LIVRO DIGITAL: CIRCULAÇÃO, PRESERVAÇÃO E FIXAÇÃO'
}

\author{
REFLEXIONES SOBRE EL LIBRO DIGITAL: \\ CIRCULACIÓN , CONSERVACIÓN Y FIJACIÓN
}

\author{
Wesley Augusto Nogueira*
}

\begin{abstract}
RESUMO
Introdução: Propõe-se discutir a conceituação de livro e apresentar questões referentes à introdução do livro digital e os aspectos concernentes ao seu acesso, circulação e preservação.

Objetivos: Conduzir à reflexão sobre o lugar do livro na sociedade da informação e de que maneira seu uso pode potencializar seus aspectos negativos e positivos, desde o livre acesso ao conhecimento até a cisão ainda maior entre informacionalmente integrados e excluídos.

Metodologia: Trabalho de cunho teórico, desenvolvido através de levantamento bibliográfico e fontes de informação disponíveis online, seguida de análise e discussão dos conceitos pesquisados sob a luz dos objetivos propostos.

Resultados: Há considerável aumento no potencial de circulação e preservação da informação, em todas as suas esferas, a partir do desenvolvimento e utilização de dispositivos digitais.

Conclusões: A evolução e disponibilidade dos meios de comunicação e processamento de informações não podem ser consideradas como práticas de desenvolvimento se não vierem acompanhadas de políticas sociais que amplifiquem o acesso efetivo aos dados por toda a população.
\end{abstract}

Palavras-chave: Livro. Materialidade. Memória. Políticas sociais. Circulação da informação. Preservação da informação.

\footnotetext{
1 Texto baseado nos resultados obtidos na dissertação de mestrado: NOGUEIRA, Wesley Augusto. O livro no fim do livro: perspectivas para o leitor, autor e editor brasileiro sob a ótica da popularização dos novos dispositivos de leitura digital. 2013. Dissertação (Mestrado em Cultura e Informação) - Escola de Comunicações e Artes, Universidade de São Paulo, São Paulo, 2013. Disponível em: <http://www.teses.usp.br/teses/disponiveis/27/27151/tde-31012014-162744/>. Acesso em: 15 mar. 2016.

* Doutorando do Programa de Pós-Graduação em Ciências da Informação da Escola de Comunicações e Artes da Universidade de São Paulo (ECA/USP). E-mail: wesleynogueira@usp.br.
} 


\section{INTRODUÇÃO}

O que é o livro? No âmbito de uma discussão sobre o digital, sua circulação, preservação e fixação, convém, em primeiro lugar, procurar compreender o que ele é ou o que pode ser, para além do lugar-comum. Através de uma análise ensaística, de cunho teórico, pretende-se questionar e investigar de que maneira a materialidade é definidora (ou não) do objeto livro e quais os reflexos, no campo da circulação e preservação informacional, da virtualização do livro (e não apenas do texto).

A partir de um ponto de vista técnico, a ABNT (Associação Brasileira de Normas Técnicas), em sua norma NBR 6029, de 2006, define o livro como "publicação não periódica que contém acima de 49 páginas, excluídas as capas, e que é objeto de Número Internacional Normalizado para Livro (ISBN)". Essa conceituação está intrinsecamente ligada ao códice impresso, baseada não no conteúdo textual, mas, sim, material do livro, representado por seu número de páginas em folhas de papel. A aplicação da norma aos livros digitais, desse modo, é bastante frágil. Os ebooks apresentam páginas fluidas, adaptáveis, não as possuindo numeradas e fixas ${ }^{2}$ como os livros convencionais. As páginas de um livro digital, tidas aqui como porções de texto visualizáveis em tela, variam de acordo com o dispositivo e com as fontes (tamanho e tipo) e diagramação adotadas, já que são personalizáveis.

Manifesta-se, nessa limitação conceitual, o problema da citação de livros digitais. A ABNT não fez nenhum pronunciamento a respeito das especificidades relativas aos documentos digitais, limitando-se a diretrizes gerais. Não há, assim, indicação, por parte da entidade, de como elaborar referências diretas a textos responsivos como os de alguns formatos de ebooks.

Se o conceito técnico da ABNT é restritivo, sob o prisma das

\footnotetext{
2 Não se consideram nessa afirmação os formatos de composição fixa de páginas, como o PDF.
} 
fundamentações filosóficas em que se baseia o direito moderno, observa-se em Kant (2003, p. 134, grifo nosso), de maneira mais ampla, que a noção de livro abrange também o texto que contém um suporte, e, conforme a visão que prega sobre o direito privado, deve ser respeitado enquanto propriedade intelectual do autor. Define assim, o filósofo, o livro como "[...] um escrito (não importa aqui se manuscrito ou impresso, se com poucas ou muitas páginas) que representa um discurso dirigido por alguém ao público, mediante signos linguísticos visíveis" e qualquer cópia que se faça "[...] sem a permissão do autor [...]" é ilegítima.

A conceituação kantiana de livro como materialização escrita do discurso adequa-se melhor ao livro digital, embora feita mais de dois séculos antes, que a definição proposta pela ABNT. A escrita, como prática e produto, não se restringe unicamente a suportes como o papel, sendo aplicável igualmente ao texto digital. $O$ discurso por ela materializado, estando inscrito em uma tela ou uma folha, representa um livro, assim como qualquer outro suporte ou configuração que a escrita discursiva vier a possuir deve ser igualmente classificado como livro.

A partir do momento em que o livro, com auspícios prometeicos, é deslocado do suporte, desafixado, fluidificado e virtualizado (em sua materialidade, já que todo texto é virtual sem um leitor), surgem dúvidas, incertezas ou certezas sobre seu destino, um porvir que entusiasma e inquieta e que não é contemplado pela superficialidade da tecnocracia presente em parte do campo de estudos, que busca a precisão e a eficiência sem compreender a relação entre as métricas e os mensurados. O leitor, usuário, tem apenas o vício da necessidade, um fantasma vazio que vaga em busca de algo, sem identidade, desejos e relevos de personalidade.

\section{CIRCULAÇÃO, PRESERVAÇÃO E FIXAÇÃO}

Um Livro de livros. A partir desse conceito, o livro mais lido e de maior sucesso editorial da história é um livro de livros. A Bíblia, vasta coletânea de histórias e ensinamentos que constituem a diretriz moral 
dos cristãos, tornou-se sinônimo de obra extensa, com numerosas páginas, nos quais os fragmentos escritos, com sentido completo, compreendem livros internos, que, nesse aspecto, são conteúdos, não forma, e sua limitação, entre início e fim, é definida pela estrutura textual, não pela tangibilidade do suporte. O livro dentro do Livro se torna, na obra sagrada, etéreo.

Já conforme Borges (1985, p. 11) o livro assim se constitui apenas no momento de sua leitura, sem a qual é apenas papel impresso: "que são as palavras impressas em um livro? Que significam esses símbolos mortos? Nada, absolutamente. Que é um livro, se não o abrimos? É, simplesmente, um cubo de papel e couro, com folhas [...]". O conceito, proposto pelo literato argentino, de que o livro é o texto que se lê, alinha-se à noção de virtualidade defendida por Levy (1996), para quem, por sua vez, o texto é virtual e atualiza-se no momento da leitura.

Desse modo, se a prática leitura é que define o livro, as políticas públicas não devem promover apenas 0 acesso aos textos, sejam impressos ou digitais, e, sim, incentivar e desenvolver a leitura, em seu sentido pleno, de compreensão dos discursos e não apenas de decodificação dos signos. Tomando o conceito de Borges, o livro só o é quando lido, e, em Levy, apenas quando é compreendido (atualizado).

No âmbito da ficção o livro adquire frequentemente caráter simbólico e torna-se muitas vezes personagem, em obras que se poderia denominar como metalivros. Almeida (1998) desenvolve o tema e elenca textos e passagens, onde Jorge Luís Borges, Umberto Eco, Italo Calvino, Ray Bradbury, entre outros, transformam o livro em figura literária. Dentro das tramas, o livro converte-se em objeto fetiche, arraigado no comportamento do bibliófilo ou colecionador, que, por vezes, resulta no extremo da paixão, que cega o discernimento e converte-se em crime, como a bibliocleptomania. Metaforiza o universo e torna as palavras chaves de seu mistério. Elemento de decifração do absoluto, adquire também caráter sagrado e potência, elevando-se à magnitude de desempenhar a palavra divina, conforme as religiões orientais. Inverte, por fim, a ordem e alcança sua supremacia: é não 
mais o representante da palavra, mas o próprio detentor da palavra. Torna-se objeto de culto e deifica-se.

No plano da realidade, entretanto, livro assume não múltiplas personalidades, mas múltiplas possibilidades e inúmeros formatos. A definição da legislação brasileira, entretanto, ainda não compreende sua pluralidade, aproximando-se à limitação conceitual da ABNT. Para contornar o problema, tramita o projeto de lei $n^{0} .4534 / 2012^{3}$, de autoria do senador Acir Gurgacz (PDT/RO), que propõe alterar "[...] a Lei no 10.753, de 30 de outubro de 2003, que 'institui a Política Nacional do Livro', para atualizar a definição de livro e para alterar a lista de equiparados a livro." Conforme dados apresentados no site do SNEL (s.d.) (Sindicato Nacional dos Editores de Livros) ${ }^{4}$

[...] seu texto muda a redação do artigo $2^{\circ}$ da Lei 10.753 que, se aprovado, passará a vigorar da seguinte forma: "Considera-se livro, para efeitos desta Lei, a publicação de textos escritos em fichas ou folhas, não periódica, grampeada, colada ou costurada, em volumes cartonado, encadernado ou em brochura, em capas avulsas, em qualquer forma e acabamento, assim como a publicação desses textos convertidos em formato digital, magnético ou ótico, ou impressos no Sistema Braille.

O projeto alinha-se às necessidades do mercado de livro digital e atende à demanda pela redução das taxas incidentes em dispositivos digitais de leitura, que, mais baratos, apresentam maior chance de se popularizar. Entretanto, o termo "convertidos", presente no texto pode dar margem a interpretações equivocadas, ao permitir a acepção de que apenas os livros digitais originários daqueles já impressos estarão atendidos pela lei, eliminando do contexto os ebooks produzidos em formato exclusivamente digital.

3 Disponível em:

<http://www.camara.gov.br/proposicoesWeb/fichadetramitacao?idProposicao $=556891$ >. Acesso em: 18 mar. 2016.

4 Disponível em: <http://www.snel.org.br/recopi-nacional-inicio-do-cadastramento/>. Acesso em: 18 mar. 2016. 
O livro digital é um conceito que tem se expandido e a proposição de lei, apesar de avançar no entendimento do assunto, pode permanecer restritiva. No Rio de Janeiro, aplicativos didáticos começam a substituir a utilização de livros e apostilas em algumas escolas (GOMES, 2013), permitindo experiências novas aos alunos. O setor editorial desenvolve-se rumo à definição do livro não mais como produto pronto, mas como serviço a ser prestado, que não se encerra no momento da compra. No campo das obras de ficção, o lançamento do livro/app The Silent History, colocou em jogo, novamente a questão das fronteiras do livro ou das fronteiras de sua conceituação, assim como dos modos e práticas de leitura.

Peter Burke, em Uma História Social do Conhecimento, relaciona informação e economia na contemporaneidade para defender que "[...] uma das razões para se afirmar que vivemos numa sociedade da informação é que a produção e venda de informações contribui de maneira considerável para as economias mais desenvolvidas." (BURKE, 2003, p. 136). Entretanto, se o tema da circulação envolve questões de mercado e apropriação social da informação, não se pode desconsiderar a importância de sua preservação, como elemento essencial para a manutenção da memória e das manifestações culturais daqueles que a produziram.

A questão que mais inquieta os especialistas é o aspecto da digitalização e a posterior preservação de documentos. $O$ projeto Google Books, referência na questão da digitalização de livros e que pretende transferir para seus servidores o maior número possível de obras impressas provenientes de bibliotecas públicas e particulares de vários países, inclusive o Brasil, é criticado por Robert Darnton (2010), pela falta de transparência em sua política de acesso. A realização de digitalizações dos acervos, da forma como está sendo conduzida, é o fato que mais o incomoda quando se pensa em livros digitais. Pelas diretrizes do projeto, a empresa estadunidense compromete-se a custear a atividade e oferecer uma cópia para a instituição cedente, que poderá disponibilizá-la gratuitamente aos usuários. Em contrapartida, o 
Google poderá comercializar as obras, mesmo aquelas com direitos autorais ainda vigentes. A discussão concentra-se no que parece, segundo o autor, o monopólio de uma grande quantidade de informação pela companhia, circunstância preocupante do ponto de vista da disponibilização futura desses dados, com o agravante de haver a questão da cobrança, por uma organização privada, pelo acesso a acervos formados com recursos públicos, já que o custo das coleções é muito maior que o valor da digitalização. São citados por Darnton, como exemplo de poder nocivo do monopólio informacional, os periódicos científicos, que chegam requerer o pagamento de milhares de dólares pelo acesso aos artigos por eles publicados.

A inquietação de Darnton situa-se especificamente no domínio do acesso à informação, mas há outros pontos importantes a se refletir em relação às digitalizações: a qualidade das cópias e possíveis manipulações nas imagens. Isso porque, dependendo de como é feita, do maquinário utilizado e de tratamentos inseridos, a digitalização pode ocasionar a perda (irreversível, no caso de deterioração do original) de características paratextuais e materiais importantes. Possivelmente, para o leitor não especializado, a perda seria irrelevante, mas para o estudioso das obras, especialmente as antigas e raras, um arquivo digital que exclua, por exemplo, uma marca d'água deixada no papel pelo fabricante, réglures em um manuscrito medieval ou uma anotação marginal é desastroso. Tais detalhes são informação de importância igual ou, dependendo do caso, até maior, conforme forem os objetivos, que o próprio texto em si. É imperativo requerer, assim, a preservação do exemplar original, da forma como foi recebido por seus leitores no momento de sua publicação.

Outro aspecto concernente à preservação dos exemplares referese à questão da posse e permanência das obras compradas em plataformas de comércio digital. O livro adquirido é armazenado na memória do dispositivo de leitura, mas, em caso de defeito, como se garantirá novamente seu acesso? Há sistemas de armazenamento em nuvens, embora nada garanta a disponibilidade, após o encerramento 
das atividades da empresa, do acervo adquirido, ou mesmo a estabilidade do texto presente em cada um dos exemplares, que pode ser alterado à revelia do autor ou editor em casos extremos, diferente do que ocorre com o livro impresso, que tem seu texto fixado independente da continuidade das atividades da editora que o publicou ou da livraria que o vendeu, estabilidade esta que se mantém por toda a vida útil do suporte.

Soma-se a isso a possibilidade da obsolescência tecnológica e do alto custo, para bibliotecas, por exemplo, da migração de plataformas e atualização de softwares periodicamente. Ainda assim, não se pode relegar a importância da digitalização para a preservação de itens em péssimo estado de conservação e que, invariavelmente, após degradação, são acessíveis apenas por suas cópias digitais.

A preservação da informação contida nos livros, em toda sua plenitude, textos, paratextos e formas materiais, deve ser objetivo primeiro da tecnologia digital, vista como instrumento auxiliar na manutenção da memória humana armazenada em suportes físicos. Como demonstrou Vilém Flusser (2010), quanto maior resistência à inscrição, ao desenho das letras e tipos, oferecer um determinado material, maior tende a ser a permanência da informação nele registrada. Textos esculpidos em pedra, metal e outros materiais duros, apesar da dificuldade em sua produção, chegam a durar milênios, enquanto os escritos em materiais maleáveis e de fácil composição, como o papel ou o papiro, não resistem muitos anos, especialmente em condições adversas. O que pensar então do texto virtual, aquele que com mais facilidade e menor esforço físico se produz? Seria um passo no escuro, sob o risco de grande parte da produção intelectual e documental perder-se sob simples erros de softwares, susceptibilidade a vírus e ataques digitais ou obsolescência dos meios de armazenamento? Ao mesmo tempo, como lidar com a questão da constante e crescente produção dinamizada pelas novas tecnologias? Espera-se, de fato, que a tendência se reverta e os arquivos digitais possam, concomitantemente, facilitar a inscrição e garantir a 
preservação.

Os equipamentos culturais que historicamente sempre zelaram pela manutenção e preservação dos livros são as bibliotecas. A partir dessa consideração, a pergunta que se deve fazer não é se existirão bibliotecas no futuro, mas, sim, da mesma forma que os livros, o que serão as bibliotecas do futuro. Pode-se considerar que não serão mais os espaços físicos que a humanidade tem se atentado em conservar (e também em destruir) nos últimos dois milênios da História, mas lugares de memória, digitais, capazes de resguardar a crescente e abundante contingência informacional da sociedade contemporânea. Convém lembrar que já há alguns anos a Biblioteca do Congresso Americano armazena páginas da internet (e mais recentemente, também tweets) para preservar seu conteúdo da frágil estabilidade proporcionada pelo suporte das redes digitais e da internet, na qual, segundo dados de um estudo divulgado pela Biblioteca Nacional Britânica a partir de sua base de dados, "[...] em 2013, 20\% dos sites deixaram de existir e $30 \%$ tinham mudado de endereço, em relação ao ano anterior." ${ }^{5}$

Aumentar o número de informações armazenadas, porém, demanda que haja sistemas de recuperação eficientes para que os dados preservados não se tornem, em sentido oposto, inacessíveis. A multiplicação dos livros, após a invenção da prensa de tipos móveis, embora positiva sob a perspectiva da circulação e do acesso, transformou o problema da escassez de manuscritos no de excesso dos impressos. Publicavam-se livros demais para uma população alfabetizada muito pequena e não eram raras as reclamações de que havia obras em excesso ou que já não era possível localizá-las todas. Pontua Briggs que "[...] as questões mais graves [na época] eram as de recuperação da informação e, ligada a isso, a seleção e crítica de livros e autores. Havia necessidade de novos métodos de administração da informação, assim como hoje em dia, nos primeiros tempos da Internet."

5 ENTINI, Carlos Eduardo. IIPC trabalha para salvar a memória da internet. Acervo Estadão. Disponível em: <http://acervo.estadao.com.br/noticias/acervo,iipc-trabalha-para-salvar-amemoria-da-internet,11039,0.htm>. Aceso em: 18 mar. 2016. 
(BRIGGS, 2006, p. 27).

Esse fenômeno de sobrecarga informacional, mesmo que muito aquém do que hoje se presencia, levou à criação de instrumentos para a localização dos livros. Conrad Gesner, polímata e humanista suíço que viveu no século $\mathrm{XVI}$, foi o primeiro a tentar catalogar em uma bibliografia universal tudo o que se havia publicado até então nas línguas latina, grega e hebraica, elaborando uma obra monumental, publicada em 1545, a que nomeou Bibliotheca Universalis, em que foram registrados por volta de 10000 títulos de 3000 autores ordenados alfabeticamente. Foi além ao mandar imprimir, em 1548, o Pandectae, um índice de assuntos de sua Bibliotheca, organizando-a em 21 áreas do conhecimento.

Os catálogos, além de sua função primeira de indexadores da informação bibliográfica, foram usados pelos livreiros-tipógrafos para dar conhecimento ao público dos títulos publicados em seus prelos. Imprimia-se listas de livros, como as do impressor veneziano Aldo Manuzio com seus clássicos, que eram distribuídas à população ou coladas em alguns pontos das cidades, junto às indicações de onde poderiam ser adquiridos e, no caso aldino, os preços das obras.

Sob o ponto de vista da catalogação de informações digitais, deve-se propor sistemas de recuperação da informação que sejam ainda mais efetivos que os catálogos impressos da era moderna, para que permitam a inserção e acesso rápido e efetivo de dados, ao mesmo tempo em que sejam compreensíveis às demandas individuais de cada usuário do sistema. Para isso, além do desenvolvimento, necessita-se que profissionais sejam formados ou atualizados para lidarem com a complexidade que frequentemente envolve sua administração, bem como que haja políticas de gestão adequadas aos seus objetivos e particularidades.

O título proposto para estas reflexões suscita uma dubiedade útil no contexto apresentado. O termo "fixação" pode ser compreendido, aqui, no sentido de uma ideia fixa, que contrapõe às ideias conservadoras daqueles que defendem a concepção dualista do livro, 
apenas impresso ou apenas digital, bem como representa a noção de fixação sob o ponto de vista de sua estabilidade, no caso dos livros, de seu conteúdo. Os livros digitais são altamente atualizáveis, fluidos, instáveis, características importantes para que se adéquem às demandas sociais contemporâneas, mas suscetíveis à impermanência de suas informações em longo prazo. Já o livro convencional, que uma vez impresso manterá seu texto fixado pelo tempo que o suporte existir, tem suas funções limitadas às próprias fronteiras físicas do papel, embora a informação que em nele está contida tenda a manter-se bem estabelecida. Cabe questionar, em livros dinâmicos como os digitais, o que será da representação do passado se suas informações estão sempre no tempo presente. Um romance, um ensaio, uma pesquisa, um relatório, entre outros, atualizados são úteis para continuamente permanecerem atendendo às necessidades de seus usuários, mas, do ponto de vista histórico, da recomposição do tempo passado, é o texto fixo que permite reconstituir a memória que se perde entre gerações.

O livro digital, a partir de sua condição de tornar os textos líquidos, eleva o tema da preservação a um patamar superior: o da memória. Se por um lado as plataformas digitais permitem que uma quantidade nunca antes vista de expressões culturais sejam produzidas e publicadas, por outro põe em xeque a decisão do que preservar a partir do momento em que muitas dessas manifestações não perdurarão para além do próprio tempo de sua produção.

Quando gigantes multinacionais do comércio de cultura, como Apple, Google e Amazon, concentram para si a gestão de quase toda a produção criativa dos países, sob quais interesses e custos decidirão 0 que deve ou não ser preservado? Ainda, em um cenário onde a informação parece saturar toda a capacidade de reminiscência individual ou coletiva, anestesiando os sentidos, o que será lembrado e como se constituirá a memória das sociedades? Como lidar com informações provenientes das tecnologias digitais, rios de Heráclito, que, embora pareçam os mesmos, nunca são os mesmos? Jacques Le Goff atenta para a questão quando define que "[...] tornarem-se senhores da 
memória e do esquecimento é uma das grandes preocupações das classes, dos grupos, dos indivíduos que dominaram e dominam as sociedades históricas." (LE GOFF, 1990, p. 427).

Os profissionais da informação têm o desafio, portanto, de junto à difusão da informação digital, preservá-la, torná-la acessível e, sobretudo, encontrar mecanismos de mantê-la com as características das circunstâncias em que foi produzida. A economia de espaço em disco, no entanto, pode levar à economia de se conservar apenas versões mais recentes dos arquivos, impedimento que os dispositivos de armazenamento com ampla capacidade que estão sendo desenvolvidos podem solucionar. Recentemente foi desenvolvido no Reino Unido um dispositivo com capacidade para 360Tb (Terabytes) de informação, o suficiente para estocar quase todos os dados coletados pela Biblioteca do Congresso Americano na internet desde 2000, quando se iniciou o projeto (422 Terabytes em maio de $2013^{6}$ ). Com base em vidro, pode resistir a temperaturas acima de $1000^{\circ} \mathrm{C}$, e parece não perder dados ou corromper arquivos ao longo do tempo, tornando-os resistentes durante o período praticamente ilimitado de conservação do suporte (ANTHONY, 2013).

Em um contexto onde o desenvolvimento tecnológico torna possível o armazenamento de informações em volumes inéditos, a partir de dispositivos que podem sobreviver ao próprio ser humano, reitera-se a emergência de que sua produção, circulação e uso sejam democratizados. É comum que periódicos e, em alguns casos, congressos especializados em editoria e história do livro, identifiquem os ereaders como a revolução do livro e as redes digitais como a revolução no acesso à informação. Revolução no âmbito dos suportes, certamente, mas é correto falar em revolução que não seja socialmente justa e proporcione a toda população igual oportunidade de acesso? Apenas atender ao mesmo público que já tem acesso ao livro pode ser

${ }^{6}$ Disponível em: <http://www.loc.gov/webarchiving/faq.html\#faqs_05>. Acesso em: 19 mar. 2016. 
revolucionário? O desenvolvimento do livro impresso certamente ampliou a fronteira de dos que podiam possuir ou ler um livro, mas ainda é necessário observar se haverá políticas públicas que façam o mesmo com o livro digital. É nesse ponto, onde o conjunto das técnicas deixa de ser frio e voltar-se apenas a si mesmo e a pequenas parcelas da sociedade, que a educação para a informação, além do mero acesso, mostra-se indispensável.

Vive-se em uma teórica sociedade da informação, mas, na prática, o que se observa é que a educação para o acesso à informação é inexistente até nas escolas particulares, consideradas de melhor qualidade, e nas universidades, onde professores e alunos se prendem a uma bibliografia rígida e pouco suscetível a adaptações. A introdução de uma disciplina, "informação", que ensinasse sua recuperação eficiente, seria um passo introdutório para a inserção dos alunos e posteriores cidadãos de maneira efetiva em uma sociedade informacional.

Para além de simplesmente serem aptos a acessarem os dados fartamente disponibilizados, prescinde-se que os sujeitos sejam capazes de utilizá-los efetivamente, trabalhá-los, moldá-los, apreendê-los, não se valendo apenas de seu fator instrumental, ao deixar de vê-los apenas como satisfação de necessidades imediatas, mas, sim, ferramente de caráter educacional e formador, que permite o deslocamento do papel de consumidor para o de protagonista, com o auspício de demolir a fronteira entre inforicos, os que têm autonomia de acessar e compreender a informação de que necessitam, e infopobres, que não a possuem.

Nesse aspecto, surgem os dispositivos de informação, como a biblioteca, equipamento de difusão cultural, não apenas de conservação, como mediadoras entre as comunidades e o conhecimento. Como ferramenta de instrução de massas, deveria vislumbrar a lógica de todos os usuários e não de apenas uma parte. Para isso, através do diálogo e da dialogia, deve-se acabar com a tradição de se assimilar as populações às premissas da biblioteca, possibilitando que deixe de ser 
apenas um serviço de informação e conservação para estabelecer o papel de dispositivo educacional. Mais do que isso, é necessário que as bibliotecas deixem de ser vistas como organismos invasores, estranhos, estrangeiros representantes de classes ou poderes aos quais os habitantes dos bairros pobres resistem em aceitar. É necessário que se sintam integrados e representados pelo equipamento, que nele encontrem a cultura de sua comunidade e possam exercer sua livre expressão. As bibliotecas, museus, espaços culturais, devem abranger não apenas o conhecimento dominante, erudito, elitizado ou canonizado pela crítica, mas também aquele periférico, produzido por indivíduos periféricos, tanto social como geograficamente nos centros urbanos.

É importante, ainda, para que todos possam ascender ao conhecimento através da informação, que se rompa com o caráter monológico, da velha máxima emissor-receptor, pondo fim à visão instrumentalista dos equipamentos culturais. Os ereaders, ao permitirem experiências inovadoras de leitura tornam-se ferramentas importantes nesse cenário, embora não elementares. Ao possibilitar o acesso a grandes e diversificados acervos, reduzem a problemática da falta de material nas bibliotecas, bem como permitem que experiências de leitura sejam compartilhadas pela rede de internet com sua comunidade, mas são incipientes se não vierem acompanhados de políticas públicas adequadas.

\section{UMA CONCLUSÃO INCONCLUSA}

As questões e reflexões apresentadas são considerações que se manifestam durante o fluxo nebuloso de suportes que ora se presencia. Pensar sobre os conceitos, as aplicações e as dinâmicas políticas e sociais envolvidas neste trânsito é imprescindível, junto aos estudos técnico-pragmáticos sobre o tema. O pensamento teórico nem sempre apresenta respostas prontas, conclusões ou considerações finalizadas, embora a tendência positivista de parte da comunidade científica tenda a fazer crer que há apenas um caminho a se percorrer. 
Assim, não se pretende concluir, mas apresentar o quão importante são as questões apresentadas para o contexto da circulação e preservação da informação. E o centro a que todas convergem é a educação para a informação, como processo fundamental para a constituição de uma geração de jovens aptos a lidar com a torrente de dados produzida em nossa sociedade, que pode ser dinamizada pelo uso adequado de ereaders. Ao comportar uma miríade de textos no dispositivo, os aparelhos ampliam o contato entre os diversos saberes através de links e notas que são automaticamente acessíveis, bem como disponibilizam recursos bibliográficos de referência, como enciclopédias, dicionários, catálogos, entre outros. Mas, para que isso seja possível, novamente se insiste, é necessário que o leitor/usuário tenha domínio das funções do equipamento e dos mecanismos de acesso e circulação da informação disponível.

Os leitores digitais têm potencial, portanto, para renovar velhas práticas, como a manutenção de uma lógica linear de transmissão da informação, entre centro e periferia, através da atuação em um contexto reticular e multiforme que compõe a sociedade da informação. Se efetivo, seu uso pode constituir uma rede de leitores que se comunicam, de fato. Ao reduzir o suporte à virtualidade, o livro digital demonstra que é importante não apenas o material, mas o texto, bem como, ao possibilitar a interação, que não apenas o texto interessa, mas também a relação com seu leitor e deste com a sociedade.

\section{REFERÊNCIAS}

ALMEIDA, Marco Antônio. O personagem-livro. In: CONGRESSO BRASILEIRO DE CIÊNCIAS DA COMUNICAÇÃO - INTERCOM, 21., 1998, Recife. Anais eletrônicos... Recife: INTERCOM, 1998. Disponível em:

<http://www.portcom.intercom.org.br/pdfs/f1b80afe4f6bb8a04190167cf6 d0a257.PDF>. Acesso em: 18 mar. 2016. 
ANTHONY, Sebastian. Five-dimensional glass memory can store 360TB per disc, rugged enough to outlive the human race. 10 jul. 2013. Disponível em: <http://www.extremetech.com/extreme/160928five-dimensional-glass-memory-can-store-360tb-per-disc-ruggedenough-to-outlive-the-human-race>. Acesso em: 19 mar. 2016.

ASSOCIAÇÃO BRASILEIRA DE NORMAS TÉCNICAS - ABNT. NBR 6029: Informação e documentação - Livros e folhetos - Apresentação. Rio de Janeiro, 2006.

BORGES, Jorge Luis. Cinco Visões Pessoais. Brasília: UNB, 1985.

BRIGGS, Asa; BURKE, Peter. História Social da Mídia: de Gutenberg à Internet. 2. ed. Rio de Janeiro: Zahar, 2006.

BURKE, Peter. Uma história social do conhecimento: de Gutemberg a Diderot. Rio de Janeiro: Jorge Zahar, 2003.

DARNTON, Robert. A Questão dos Livros: presente, passado e futuro. São Paulo: Companhia das Letras, 2010.

FLUSSER, Vilém. A escrita: há futuro para a escrita? São Paulo: Annablume, 2010.

GOMES, Helton Simões. Com cara de game, app para tablets em 3D substitui livro didático no Rio. Disponível em: <http://g1.globo.com/tecnologia/noticia/2013/04/com-cara-de-game-apppara-tablets-em-3d-substitui-livro-didatico-no-rio.html>. Acesso em: 19 mar. 2013.

KANT, Immanuel. A metafísica dos costumes. Bauru, SP: EDIPRO, 2003.

LE GOFF, Jacques. História e Memória. Campinas: UNICAMP, 1990.

LÉVY, Pierre. O Que é Virtual?. Rio de Janeiro: Editora 34, 1996.

Title

Reflexions about the digital book: circulation, preservation and fixation

\section{Abstract}

Introduction: It is proposed to discuss the book concept and present issues related to the introduction of digital book and aspects associated to its access, circulation and preservation.

Objectives: To conduct a reflection about the place of the book in the information society and how its use can boost its positive and negative aspects, from the free access to knowledge to further split between integrated and 
informationally excluded.

Methodology: Theoretical nature work, developed according to literature and available online information sources, followed by analysis and discussion of the concepts studied in the light of the proposed objectives.

Results: There is considerable increase in the potential of circulation and preservation of information in all its spheres, from the development and use of digital devices.

Conclusions: The development and availability of media devices and processing information methods can't be considered as a development practices if they come not accompanied by social policies that amplify effective access to data for the whole population.

Key words: Book. Materiality. Memory. Social policies. Flow of information. Information preservation.

\section{Titulo}

Reflexiones sobre el libro digital: circulación, conservación y fijación

\section{Resumen}

Introducción: Se propone discutir el concepto de libro y los temas actuales relacionados con la introducción del libro digital y los aspectos relacionados con su acceso, circulación y preservación.

Objetivos: Realizar una reflexión sobre el lugar del libro en la sociedad de la información y cómo su uso puede mejorar sus aspectos positivos y negativos, desde el libre acceso al conocimiento a una mayor división entre integrados y excluidos informativamente.

Metodología: Trabajo de carácter teórico, desarrollado a través de la literatura y las fuentes de información disponibles en línea, seguido por la análisis y la discusión de los conceptos estudiados a la luz de los objetivos propuestos.

Resultados: Existe un considerable aumento en el potencial de circulación y conservación de la información en todas sus esferas, a partir del desarrollo y uso de dispositivos digitales.

Conclusiones: El desarrollo y la disponibilidad de medios de comunicación y procesamiento de la información no pueden ser considerados como prácticas de desarrollo si no vienen acompañadas de políticas sociales que amplifican el acceso efectivo a los datos de toda la población.

Palabras clave: Libro. Materialidad. Memoria. Políticas sociales. Circulación de la información. Preservación de la información.

Recebido em: 26.12.2015

Aceito em: 20.03.2016 